\title{
The Relationship with Previous Use of Community-Based Services and Informal Caregiver Support and Elderly and Informal Caregivers' Views of Living Arrangement: Analysis of Official Statistics from 2004 to 2014
}

\author{
Kailu Wang1, Stephen Chi-Kin Law², Eliza Lai-Yi Wong1* , Eng-Kiong Yeoh1 \\ ${ }^{1}$ The Jockey Club School of Public Health and Primary Care, Faculty of Medicine, The Chinese University of Hong Kong, \\ Hong Kong SAR, China \\ ${ }^{2}$ Centre for Applied Health Economics of the School of Medicine, Menzies Health Institute, Griffith University, Queensland, \\ Australia \\ Email: *lywong@cuhk.edu.hk
}

How to cite this paper: Wang, K.L., Law, S.C.-K., Wong, E.L.-Y. and Yeoh, E.-K. (2019) The Relationship with Previous Use of Community-Based Services and Informal Caregiver Support and Elderly and Informal Caregivers' Views of Living Arrangement: Analysis of Official Statistics from 2004 to 2014. Open Journal of Nursing, 9, 494-508.

https://doi.org/10.4236/ojn.2019.95042

Received: April 4, 2019

Accepted: May 19, 2019

Published: May 22, 2019

Copyright $\odot 2019$ by author(s) and Scientific Research Publishing Inc. This work is licensed under the Creative Commons Attribution International License (CC BY 4.0).

http://creativecommons.org/licenses/by/4.0/ (c) (i) Open Access

\begin{abstract}
Background and Objectives: Views on living arrangement from elderly and informal caregivers are crucial to "ageing in place". They might be related to the experience in the use of elderly care services, which remains inconclusive in previous literature. This study aimed to explore the association of previous experience in formal and informal long-term care services with views of both elderly and their informal caregivers on living arrangement. Research Design and Methods: This study adopted a cross-sectional design. Assessment records of Minimum Data Set-Home Care for community-dwelling elderly who were eligible for subsidized long-term care services in Hong Kong from 2004 to 2014 were made available. Multivariate logistic regression was applied to examine associations between both views on elder's living arrangement from the elderly, caregivers and their previous informal caregiver support, and experience in formal care services. Results: 82,306 dyads of elderly and informal caregivers were included in the analysis. The elderly with previous use of home and community-based services (OR $=0.84,95 \% \mathrm{CI} 0.80-0.88)$ and informal caregivers $(\mathrm{OR}=0.78,95 \% \mathrm{CI} 0.76-0.81)$ believed that the elderly should live away from home. Temporal trends of fewer elderly and caregivers supporting the idea of living away from home were also observed. Discussion and Implications: The results highlighted the importance of informal caregiver's support and previous utilization of formal home and community-based services. It was concluded that resources and information
\end{abstract}


of community-based care have a significant association with views on living at home also proper support services and training of care for the elderly should be made available to informal caregivers to reduce their burden.

\section{Keywords}

Long-Term Care, Elderly, Informal Caregiver, Preference, Living Arrangement, Service Utilization

\section{Introduction}

The statistics reported that in 2017, people aged 65 years and above in Hong Kong accounted for $16.5 \%$ [1] and the figure was expected to reach $26.4 \%$ by 2030 [2]. The dependence ratio was 218 per 1000 population aged 15 - 64 [3]. Under this context, the long-term care provision plays a vital role in responding to challenges arising from ageing population. Ageing in place has been advocated in the Organization for Economic Co-Operation and Development (OECD) countries globally. Its purpose is to improve life quality by maintaining the autonomy of the elderly and combining familiar environment and people with community services and supports [4] [5]. It also hopes to enhance the quality of care and sustainability of the system [5]. Efforts have been made to improve the utilization and quality of home and community-based services in many established economies [5].

Hong Kong is one typical example as over-reliance on residential care has been one of the major problems faced by long-term care (LTC) in Hong Kong. According to the latest statistics in 2014, Hong Kong experienced a relatively higher institutionalization rate of 5.7\% among those aged 65 and above than Singapore, Japan, South Korea and Taiwan, which lied roughly between $1 \%$ and $3 \%$ [6] [7]. The long waiting time of 37 months for government-subvented residential care homes for the elderly (RCHEs) was observed in 2017 [7]. This implied that the needs of the elderly for long-term care were not fully met in a proper and timely manner. Thus, policies and interventions encouraging the elders to stay at home through home and community-based services should be developed. In addition, it is essential to identify the factors with association with the views of the elderly on living away from or living at home and the extent of the association. These factors play a role in people's choice of long-term care service.

In addition to the elderly themselves, family caregivers are another essential party involved in the choice between institutionalization or ageing in place. On the one hand, the availability and quality of their assistance to the elders have an association with the views of the elderly [8] [9] and the institutionalization [10]; on the other hand, their views greatly impact on the final decision of service choice and living arrangement of the elderly [11] [12]. Caregivers being stressed and having higher burden are associated with institutionalization of elders [13] 
[14] [15]. The influential factors of caregivers' opinion on the living arrangement of the elderly include the physical function of the care recipient and caregiver being aged [16]. Apart from what has mentioned above, how their views are affected by the use of formal care services in both community settings and RCHEs remains unclear [17].

The previous experience in receiving home and community-based services might have close correlation to the views of the elderly. A systematic review on the elderly with dementia [10] pointed out that in several studies [18] [19], the experience of the elderly in home care or day care services reduced the rate of institutionalization among them; while opposite results were described in other studies [20] [21] [22]. Some studies [23] [24] reported that community-based social services and personal care services lowered the likelihood of institutionalization and delayed their admission of residential care settings. However, the relationship between more use of community services and higher preference for residential care was found in study [17]. These studies [10] [17]-[24] all assumed the impact of receiving community-based services on the decision-making of the elderly between residential care and community care; but no adequate evidence confirmed the influence of previous experience in community-based and institution-based care services on institutionalization [17] [25].

Previous use of care services and informal support can be interpreted in many ways. Firstly, the use of services is associated with the health needs of the elderly [10]. A Japanese study [26] claimed that, when their needs were controlled, more information sources and aware of local care prevention policy will increase the preference of the elderly for ageing in place. Insufficient information accessibility may be barriers of public policy to promote "ageing in place", home and community-based services [27] [28]. Previous use of such services is a way for them to acquire knowledge and information [29]. In addition to health needs and information, the accessibility to the elderly care resources and higher social participation are exhibited to be other potential factors that related to the views [8].

Moreover, various predictors for whether the elderly chose residential care as their living arrangement are also found in Hong Kong and other regions. The studies [16] [17] have confirmed the correlation of older age and greater physical functional impairment with institutionalization. Meanwhile, factors related to mental health are also found to be major predictors. For example, poor short-term memory contributed to the choice of residential care, especially among elders with dementia [17] [30] [31]. The correlation of mood factors including presentation of depressive symptoms with institutionalization was indicated in a study [15].

Based on the knowledge gaps identified above, this study aimed to find out the correlation of previous utilization of social care services with the views of both elderly and their caregivers on elder's living arrangement in Hong Kong, with other covariates being adjusted. Possible explanation of the correlation and policy implication of the results were given in the following sections. 


\section{Methods}

\subsection{Data Source}

There was a total of 184,647 official data records of elderly and self-reported primary informal caregivers (i.e. family member, domestic maid or friends and neighbors) with available information of their views of living arrangement during from October 2004 to September 2014, which was obtained from Hong Kong Social Welfare Department under the Standardized Care Need Assessment Mechanism for Elderly Services (SCNAMES). Among them, 109,082 records of elderly living in community were extracted and the rest of them (institutional-dwelling elderly) were excluded. Among these community-dwelling elderly, those who were assessed to be eligible to subsidized LTC service (i.e. with moderate or severe impairment) and have choices between residential care and community care services $(n=82,306)$ were selected for analysis. All potential applicants for subsidized LTC services were assessed by Chinese version of Minimum Data Set-Home Care (MDS-HC), a well-validated questionnaire used for assessment and care planning of community-dwelling elderly who are seeking formal care and support services in North America, Europe and Asia/Pacific Rim [32]. The physical and mental function of this group of elderly was fitted in both community and residential care. The scales for Activities of Daily Living (ADLs), Instrumental Activities of Daily Living (IADLs), cognition, communication, pain, depression, as well as medical instability and information about health status, utilization of health and social care service, living arrangement and status of informal caregivers were taken into account in the questionnaire.

\subsection{Variables}

The views of both elders and their primary informal caregiver on living arrangement of the elderly, the best indicators available in MDS-HC to describe their views of future institutionalization, were selected as dependent variables. Binary outcomes were set for these two variables: "1" indicated participants' support to live away from home; " 0 " indicated the support to live at home.

Previous experience of the elderly in being assisted by informal caregivers, previous use of home and community-based services (including services provided by day care centre and out-reaching services at home such as personal care and visiting nurse), and previous use of institutional care services were adopted as key independent variables. Other independent variables included socio-demographic variables, health-related and functional variables, caregiver-related variables and time factors, which were also used as covariates in other studies. Socio-demographic variables were age, gender, educational level, marital status, and whether or not any trade-off between daily life expenses and health/social care services was taken as an indicator of financial difficulty. ADLs, IADLs, cognition, and multi-morbidity (with 3 and above chronic diseases) were considered as health-related and functional variables. Whether the informal caregiver co-resided with the elderly and whether informal caregivers perceived 
any stress and dissatisfaction about the work were classified into caregiver-related factors. Moreover, the year when the assessment was conducted was also applied in the analysis for the adjustment of the unobserved social-cultural changes over time. These changes might correlate with the views of the elderly and caregivers but have not been captured by other independent variables yet.

\subsection{Statistical Analysis}

Stata 14.2 was applied in all statistical analyses. Descriptive statistics with chi-square tests were first performed targeting the characteristics of the sample. Afterwards, multivariate logistic regressions for the elderly with frailty and their informal caregivers were separately conducted to examine the statistical association between the two dependent variables and explanatory variables. Forward stepwise regression was used to select independent variables and finalize the models. Socio-demographic factors including age, gender, educational level and marital status was entered the regression model. As the statistically-significance of the association might be attributed to large sample size, only the variables with $95 \%$ confidence interval (CI) beyond the range of 0.9 - 1.1 (i.e. any value within $95 \%$ CI should be at least $10 \%$ different from 0 ) in the multivariate regression were highlighted and discussed in this paper to ensure these reported differences were meaningful.

The study received research ethics approval from the Survey and Behavioral Research Ethics Committee of the Chinese University of Hong Kong.

\section{Results}

\subsection{Results of Descriptive and Univariate Analysis}

The views and characteristics of the sample were shown in Table 1 and Table 2. Among the participants, $41 \%$ of the elderly and $67 \%$ of caregivers agreed that the elderly should live away from home. The average age of the elderly was 80.6 years old and females accounted for $60.0 \%$. Based on univariate analysis (Table 2 ), the majority of elders in the sample with higher level of ADL impairment or subject to trade-offs supported the idea of living away from home; while those being married, not living alone, with higher educational level, with IADL, cognitive impairment, undertaking caregiver-perceived burden, or with previous use of formal home and community-based care services mostly showed a different view.

Table 1. Characteristics and views of elderly's living arrangement of the elderly and caregivers.

\begin{tabular}{lccc}
\hline \multicolumn{1}{c}{ Characteristics } & Percentage & Characteristics & Percentage \\
\hline \multicolumn{1}{c}{ Socio-demographic factors } & & Factors about previous use of services \\
Age of elderly & $80.6 \pm 7.7$ & Prior help from informal carers & \\
Gender & & No & $57.6 \%$ \\
\hline
\end{tabular}




\section{Continued}

\begin{tabular}{|c|c|c|c|}
\hline Male & $40.0 \%$ & Yes & $42.5 \%$ \\
\hline Female & $60.0 \%$ & \multicolumn{2}{|c|}{ Prior use of home \& community-based care } \\
\hline Educational level & & No & $86.4 \%$ \\
\hline Below primary school & $69.1 \%$ & Yes & $13.6 \%$ \\
\hline Primary & $8.7 \%$ & Prior use of RCHEs ${ }^{c}$ & \\
\hline Secondary & $11.3 \%$ & No & $93.2 \%$ \\
\hline Higher education & $2.6 \%$ & Yes & $6.8 \%$ \\
\hline Other & $8.3 \%$ & Time factor: Fiscal year & \\
\hline Marital status & & 2004-2005 & $5.3 \%$ \\
\hline Never married & $4.0 \%$ & 2005-2006 & $7.0 \%$ \\
\hline Currently married & $42.7 \%$ & 2006-2007 & $8.1 \%$ \\
\hline Widowed/separated/divorced & $53.0 \%$ & $2007-2008$ & $9.2 \%$ \\
\hline Other & $0.2 \%$ & 2008-2009 & $9.9 \%$ \\
\hline Tradeoff between care services $\&$ dai & expenses & $2009-2010$ & $10.1 \%$ \\
\hline No & $98.1 \%$ & 2010-2011 & $11.6 \%$ \\
\hline Yes & $1.9 \%$ & 2011-2012 & $12.0 \%$ \\
\hline Life quality-related factors & & $2012-2013$ & $12.6 \%$ \\
\hline $\mathrm{ADL}^{\mathrm{a}}$ impairment & & 2013-2014 & $14.4 \%$ \\
\hline No & $29.9 \%$ & Caregiver-related factors & \\
\hline Yes & $70.1 \%$ & Whom the elderly is living with & \\
\hline IADL $^{\mathrm{b}}$ impairment & & Living alone & $21.0 \%$ \\
\hline No & $1.8 \%$ & With spouse only/and others & $37.8 \%$ \\
\hline Yes & $98.3 \%$ & With children & $32.3 \%$ \\
\hline Cognitive problem & & With others & $8.8 \%$ \\
\hline No & $10.6 \%$ & Carer perceived burden & \\
\hline Yes & $89.4 \%$ & No & $14.1 \%$ \\
\hline Multi-morbidity & & Yes & $85.9 \%$ \\
\hline$<3$ diseases & $37.7 \%$ & & \\
\hline$\geq 3$ diseases & $62.3 \%$ & & \\
\hline
\end{tabular}

Views of living arrangement

Elderly's view

$\begin{array}{ll}\text { Better to live at home } & 58.5 \% \\ \text { Better to live away from home } & 41.5 \%\end{array}$

Caregiver's view

$\begin{array}{lr}\text { Better to live at home } & 33.1 \% \\ \text { Better to live away from home } & 66.9 \% \\ \text { Total }(\mathrm{n}=82,306) & 100.0 \%\end{array}$

$33.1 \%$

$100.0 \%$

Total $(\mathrm{n}=82,306)$

$100.0 \%$

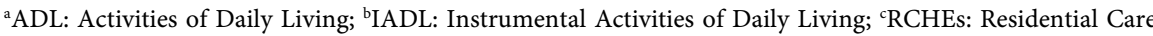
Homes for Elderly. 
Table 2. Characteristics of elderly in the study sample and factors associated with views of living arrangement of the elderly and caregivers from univariate analysis.

\begin{tabular}{|c|c|c|c|c|c|c|}
\hline & $\begin{array}{l}\text { Elderly feelit } \\
\text { better to } \\
\text { liveat home } \\
(n=48,186)\end{array}$ & $\begin{array}{c}\text { Elderly feelit better } \\
\text { to liveaway from } \\
\text { home }(n=34,120)\end{array}$ & $\begin{array}{c}\text { P-value } \\
\text { (t-test/Chi- } \\
\text { square test) }\end{array}$ & $\begin{array}{l}\text { Caregivers } \\
\text { feelelderly better } \\
\text { to liveat home } \\
(\mathrm{n}=27,266)\end{array}$ & $\begin{array}{l}\text { Caregivers feelelderly } \\
\text { better to live away } \\
\text { from home } \\
(\mathrm{n}=55,040)\end{array}$ & $\begin{array}{c}\text { P-value } \\
\text { (t-test/Chi- } \\
\text { square test) }\end{array}$ \\
\hline \multicolumn{7}{|l|}{ Socio-demographic factors } \\
\hline Age of elderly & $80.8 \pm 7.7$ & $80.4 \pm 7.6$ & $<0.001^{\star *}$ & $80.2 \pm 7.8$ & $80.90 \pm 7.6$ & $<0.001^{\star *}$ \\
\hline Gender & & & 0.312 & & & 0.794 \\
\hline Male & $58.3 \%$ & $41.7 \%$ & & $33.1 \%$ & $66.9 \%$ & \\
\hline Female & $58.7 \%$ & $41.3 \%$ & & $33.2 \%$ & $66.8 \%$ & \\
\hline Educational level & & & $<0.001^{\star *}$ & & & $<0.001^{* *}$ \\
\hline Below primary school & $58.7 \%$ & $41.3 \%$ & & $32.3 \%$ & $67.7 \%$ & \\
\hline Primary & $56.0 \%$ & $44.0 \%$ & & $35.0 \%$ & $65.0 \%$ & \\
\hline Secondary & $59.7 \%$ & $40.3 \%$ & & $37.1 \%$ & $62.9 \%$ & \\
\hline Higher education & $63.9 \%$ & $36.1 \%$ & & $40.4 \%$ & $59.6 \%$ & \\
\hline Other & $56.9 \%$ & $43.1 \%$ & & $30.2 \%$ & $69.8 \%$ & \\
\hline Marital status & & & $<0.001^{* *}$ & & & $<0.001^{\star *}$ \\
\hline Never married & $46.3 \%$ & $53.7 \%$ & & $39.4 \%$ & $60.6 \%$ & \\
\hline Currently married & $61.1 \%$ & $38.9 \%$ & & $33.8 \%$ & $66.2 \%$ & \\
\hline Widowed/separated/divorced & $57.5 \%$ & $42.6 \%$ & & $32.1 \%$ & $67.9 \%$ & \\
\hline Other & $56.1 \%$ & $43.9 \%$ & & $38.9 \%$ & $61.1 \%$ & \\
\hline Tradeoff between care services $\&$ dai & life expenses & & $<0.001^{* *}$ & & & $<0.020^{*}$ \\
\hline No & $58.3 \%$ & $41.7 \%$ & & $33.0 \%$ & $67.0 \%$ & \\
\hline Yes & $46.6 \%$ & $53.4 \%$ & & $36.1 \%$ & $63.9 \%$ & \\
\hline \multicolumn{7}{|l|}{ Life quality-related factors } \\
\hline $\mathrm{ADL}^{\mathrm{a}}$ impairment & & & $<0.001^{\star *}$ & & & $<0.001^{\star *}$ \\
\hline No & $60.5 \%$ & $39.5 \%$ & & $40.9 \%$ & $59.1 \%$ & \\
\hline Yes & $57.7 \%$ & $42.3 \%$ & & $29.8 \%$ & $70.2 \%$ & \\
\hline $\mathrm{IADL}^{\mathrm{b}}$ impairment & & & $0.023^{*}$ & & & $<0.001^{\star \star}$ \\
\hline No & $55.6 \%$ & $44.4 \%$ & & $53.0 \%$ & $47.0 \%$ & \\
\hline Yes & $58.6 \%$ & $41.4 \%$ & & $32.8 \%$ & $67.2 \%$ & \\
\hline Cognitive problem & & & $<0.001^{\star *}$ & & & $<0.001^{\star *}$ \\
\hline No & $51.0 \%$ & $49.0 \%$ & & $43.5 \%$ & $56.5 \%$ & \\
\hline Yes & $59.4 \%$ & $40.6 \%$ & & $31.9 \%$ & $68.1 \%$ & \\
\hline Multi-morbidity & & & $0.001^{*}$ & & & $0.029^{*}$ \\
\hline$<3$ diseases & $57.8 \%$ & $42.2 \%$ & & $33.6 \%$ & $66.4 \%$ & \\
\hline$\geq 3$ diseases & $59.0 \%$ & $41.0 \%$ & & $32.9 \%$ & $67.2 \%$ & \\
\hline \multicolumn{7}{|l|}{ Caregiver-related factors } \\
\hline Whom the elderly is living with & & & $<0.001^{* *}$ & & & $<0.001^{\star *}$ \\
\hline Living alone & $48.6 \%$ & $51.4 \%$ & & $34.8 \%$ & $65.2 \%$ & \\
\hline
\end{tabular}




\section{Continued}

$\begin{array}{lllll}\text { With spouse only/and others } & 61.7 \% & 38.3 \% & 33.4 \% & 66.6 \% \\ \text { With children } & 60.3 \% & 39.7 \% & 31.1 \% & 68.9 \% \\ \text { With others } & 62.5 \% & 37.6 \% & 35.4 \% & 64.6 \%\end{array}$

Carer perceived burden

$<0.001^{* *}$

$<0.001^{\star *}$

$\begin{array}{lllll}\text { No } & 56.1 \% & 43.9 \% & 34.8 \% & 65.2 \% \\ \text { Yes } & 59.0 \% & 41.1 \% & 32.9 \% & 67.2 \%\end{array}$

Factors about previous use of services

Prior help from informal carers

$<0.001^{* *}$

$<0.001^{* *}$

\begin{tabular}{l|ll} 
No & $58.3 \%$ & $41.8 \%$ \\
Yes & $59.5 \%$ & $40.5 \%$
\end{tabular}

$\begin{array}{ll}29.4 \% & 70.6 \% \\ 35.9 \% & 64.1 \%\end{array}$

Prior use of home \& community-based care

\begin{tabular}{l|ll} 
No & $58.0 \%$ & $42.0 \%$ \\
Yes & $61.7 \%$ & $38.3 \%$ \\
\hline
\end{tabular}

$<0.001^{* *}$

$<0.001^{* *}$

rior use of RCHEs c

$58.5 \%$

$59.4 \%$

$41.5 \%$

$40.6 \%$

Yes

Time factor: Fiscal year

2004-2005

2005-2006

2006-2007

2007-2008

2008-2009

2009-2010

2010-2011

2011-2012

2012-2013

2013-2014
$44.9 \%$

$46.6 \%$

$49.4 \%$

$48.9 \%$

$57.2 \%$

$61.0 \%$

$61.9 \%$

$65.5 \%$

$64.0 \%$

$66.7 \%$

$<0.001^{* *}$

$55.1 \%$

$53.4 \%$

$50.6 \%$

$51.1 \%$

$42.8 \%$

$39.0 \%$

$38.2 \%$

$34.5 \%$

$36.0 \%$

$33.3 \%$

\begin{tabular}{|c|c|}
\hline $33.2 \%$ & $66.8 \%$ \\
\hline $30.4 \%$ & $69.6 \%$ \\
\hline
\end{tabular}

0.176

0.762

$\begin{array}{ll}33.1 \% & 66.9 \% \\ 32.9 \% & 67.1 \%\end{array}$

(1)

$27.6 \%$

$<0.001^{\star *}$

$27.3 \%$

$72.4 \%$

$28.5 \%$

$72.7 \%$

$27.5 \%$

$71.5 \%$

$31.0 \%$

$72.5 \%$

$33.0 \%$

$69.0 \%$

$34.7 \%$

$67.0 \%$

$38.7 \%$

$65.4 \%$

$35.0 \%$

$61.3 \%$

$38.3 \%$

$65.0 \%$

$61.7 \%$

${ }^{*} \mathrm{P}<0.05,{ }^{* *} \mathrm{P}<0.001 .{ }^{\mathrm{a}} \mathrm{ADL}$ : Activities of Daily Living; bIADL: Instrumental Activities of Daily Living; ${ }^{\mathrm{R} C H E s}$ Residential Care Homes for Elderly. Differences in key variables are highlighted in shadow.

Among caregivers in the sample, those caring the elderly who had ADL, IADL and cognitive impairment and had received more home and community-based services were more likely to feel it better for their elderly to live away from home. Previous use of RCHEs exhibited no significant association with the views of the elderly and caregivers; hence, it was not taken as an independent variable in the multivariate analysis.

\subsection{Results of Multivariate Regression on Elderly People's Views about Living Arrangement}

Results of multivariate regression model for living arrangement views of the elderly and their informal caregivers were shown in Table 3 . For the views of the 
Table 3. Factors associated with views for living arrangement of the elderly and caregivers from multivariate logistic analysis.

\begin{tabular}{ccccc}
\hline & \multicolumn{2}{c}{$\begin{array}{c}\text { Elderly feel it betterto live } \\
\text { away from home }\end{array}$} & \multicolumn{2}{c}{$\begin{array}{c}\text { Caregivers feelit better for } \\
\text { elderly to live away from home }\end{array}$} \\
\hline & OR & $95 \%$ CI & OR & $95 \%$ CI \\
\hline Socio-demographic factors & 1.06 & $(1.03,1.10)^{* *}$ & 1.03 & $(1.00,1.06)$ \\
Age & 1.00 & $(1.00,1.00)^{* *}$ & 1.00 & $(1.00,1.00)$ \\
Age ${ }^{2}$ & 0.94 & $(0.90,0.97)^{\star}$ & 0.89 & $(0.86,0.92)^{* *}$ \\
Gender & & & &
\end{tabular}

Educational level (“Below primary school” as reference)

$\begin{array}{ccccc}\text { Primary } & 1.15 & (1.09,1.22)^{* *} & 0.95 & (0.90,1.00) \\ \text { Secondary } & 0.99 & (0.94,1.04) & 0.87 & (0.83,0.91)^{* *} \\ \text { Higher education } & 0.81 & (0.73,0.90)^{* *} & 0.74 & (0.67,0.81)^{* *} \\ \text { Other } & 1.04 & (0.98,1.10) & 1.04 & (0.98,1.10)\end{array}$

Marital status ("Never married" as reference)

\begin{tabular}{|c|c|c|c|c|}
\hline Currently married & 0.71 & $(0.64,0.79)^{\star \star}$ & 0.85 & $(0.76,0.94)^{\star}$ \\
\hline Widowed/separated/divorced & 0.74 & $(0.67,0.81)^{\star \star}$ & 0.99 & $(0.91,1.08)$ \\
\hline Other & 0.74 & $(0.53,1.04)$ & 0.99 & $(0.71,1.39)$ \\
\hline $\begin{array}{c}\text { Trade-off between care services } \\
\text { \& daily life expenses }\end{array}$ & 1.44 & $(1.28,1.62)^{\star \star}$ & - & - \\
\hline \multicolumn{5}{|l|}{ Life quality-related factors } \\
\hline ADL impairment ${ }^{\mathrm{a}}$ & 1.22 & $(1.18,1.27)^{\star *}$ & 1.53 & $(1.48,1.58)^{\star \star}$ \\
\hline IADL impairment ${ }^{\mathrm{b}}$ & 0.89 & $(0.78,1.01)$ & 1.53 & $(1.36,1.71)^{\star \star}$ \\
\hline Cognitive problem & 0.75 & $(0.72,0.79)^{\star *}$ & 1.57 & $(1.49,1.64)^{\star x}$ \\
\hline
\end{tabular}

\section{Caregiver-related factors}

Whom the elderly is living with("Living alone" as reference)

\begin{tabular}{|c|c|c|c|c|}
\hline With spouse & 0.54 & $(0.50,0.58)^{* *}$ & 0.84 & $(0.78,0.91)^{\star * *}$ \\
\hline With children & 0.59 & $(0.56,0.62)^{\star \star}$ & 0.81 & $(0.77,0.85)^{\star \star}$ \\
\hline With others & 0.53 & $(0.50,0.57)^{\star *}$ & 0.73 & $(0.69,0.78)^{* *}$ \\
\hline Carer perceived burden & 1.26 & $(1.20,1.32)^{\star \star}$ & 1.14 & $(1.09,1.20)^{\star *}$ \\
\hline \multicolumn{5}{|l|}{ Prior use of services } \\
\hline Prior help from informal carers & 0.91 & $(0.88,0.94)^{\star \star}$ & 0.78 & $(0.76,0.81)^{\star *}$ \\
\hline $\begin{array}{l}\text { Prior use of home and } \\
\text { community-based services }\end{array}$ & 0.84 & $(0.80,0.88)^{\star *}$ & - & - \\
\hline
\end{tabular}

\section{Time factor}

Fiscal Year (2004-2005 as reference)

$\begin{array}{lllll}2005-2006 & 0.93 & (0.86,1.01) & 0.99 & (0.90,1.08) \\ 2006-2007 & 0.83 & (0.77,0.90)^{* *} & 0.92 & (0.84,1.01) \\ 2007-2008 & 0.85 & (0.79,0.92)^{\star *} & 0.99 & (0.91,1.08) \\ 2008-2009 & 0.60 & (0.56,0.65)^{* *} & 0.81 & (0.74,0.88)^{\star *}\end{array}$


Continued

\begin{tabular}{lllll}
\hline $2009-2010$ & 0.46 & $(0.41,0.51)^{* *}$ & 0.75 & $(0.69,0.81)^{\star *}$ \\
$2010-2011$ & 0.50 & $(0.45,0.56)^{\star *}$ & 0.69 & $(0.63,0.74)^{\star *}$ \\
$2011-2012$ & 0.42 & $(0.39,0.46)^{\star *}$ & 0.57 & $(0.52,0.61)^{\star *}$ \\
$2012-2013$ & 0.46 & $(0.42,0.49)^{\star *}$ & 0.66 & $(0.61,0.72)^{\star *}$ \\
$2013-2014$ & 0.40 & $(0.38,0.43)^{* *}$ & 0.58 & $(0.53,0.62)^{\star *}$ \\
\hline
\end{tabular}

${ }^{\star} \mathrm{P}<0.05,{ }^{*} \mathrm{P}<0.001 .{ }^{\mathrm{a}} \mathrm{ADL}$ : Activities of Daily Living; ${ }^{\mathrm{b} I A D L}$ : Instrumental Activities of Daily Living; $\wedge$ Cells marked with "." stand for the variables were removed from the regression model by forward-selection stepwise regression. Adjusted odds ratios of key variables are highlighted in shadow.

elderly, multi-morbidity was removed from the model in forward-stepwise selection due to its larger p-value than the pre-set level of 0.05 . The elderly who previously received home and community-based care services $(\mathrm{OR}=0.84,95 \%$ CI 0.80 - 0.88) were less likely to support the idea of living away from home. Higher ADL impairment $(\mathrm{OR}=1.22,95 \%$ CI 1.18 - 1.27) and lower cognitive impairment $(\mathrm{OR}=0.75,95 \% \mathrm{CI} 0.72-0.79)$ as health-related and functional factors, as well as living alone and with caregivers perceiving burden were found to be associated with views of this living arrangement. Moreover, a clear decreasing trend in likelihood of views on living away from home was observed.

\subsection{Informal Caregivers' Views of Living Arrangement}

For living arrangement views of informal caregivers, trade-offs, multi-morbidity and previous use of home and community-based services were removed in forward-stepwise selection as all of their significant levels did not meet the pre-set criteria $\mathrm{p}<0.05$. Informal caregivers were less likely to agree the idea of living away from home $(\mathrm{OR}=0.78,95 \% \mathrm{CI} 0.76-0.81)$. With other factors being controlled, gender, instead of age was found to be correlated with the views of caregivers on living arrangement. Caregivers serving elderly with functional impaired were also more likely to support the idea of living away from home. Similar as the views of the elderly, the views of caregivers were found correlated to the elderly living alone and caregiver perceiving burden. The decreasing temporal trend of adjusted ORs was also observed here.

\section{Discussions}

This was the first study based on 10-year registry data with all applicants of subsidized LTC system, which gave us a clear profile of views on living arrangement of the elderly with long-term care needs in Hong Kong. It was also one of a few studies focusing on the association between the use of home and community-based care and views on living arrangement and institutionalization in Hong Kong. In line with earlier studies [15] [16], results of the present analysis revealed that previous use of home and community-based care services, such as centre-based day care services, home-based personal care services for elderly with ADL impairment, were associated with elderly people's views on ageing in 
place. On one hand, this previous experience suggested higher accessibility of health and social care with elderly people needs being controlled. Available and accessible long-term care services in the community might reduce elders' perceived barriers to live at home [33]. This explanation was also highlighted in other studies that shorter distance to community healthcare facilities reduced the choice of institutionalization [8]. On the other hand, the elderly with frailty acquired knowledge and information about the care from this experience, which allowed them to get familiar with services and develop trusts to care staff and institutions in their community, especially for formal home and community care services [26]. Further researches are needed to confirm whether accessibility of information on community services impacts elderly people's opinion on ageing in place.

When caregivers' burden and other factors were controlled, support of informal caregivers was associated with their opinion that the elderly should live at home. This might be partly because the helping behavior came from their attitude of preferring the elderly to live at home, which needs to be examined in longitudinal studies. However, previous experience in formally serving the elderly was found to have no association with the caregivers' attitudes. This might because current home and community-based care services did not target to alleviate the burden of the caregivers. Moreover, neither elderly people's nor caregivers' views got changed due to previous use of RCHEs services. It might suggest relevant experience in receiving elderly institution care had little association with their attitudes.

Both informal caregivers and community care facilities providing home and community-based care play important roles in promoting ageing in place. It is a prompt for policy makers to consider improving the provision of the community care facilities and providing preventive community-based LTC services before functions of elderly deteriorate dramatically. It is likely that such preventive services could enable the elderly to live independently in the community. For instance, there are community-based preventive care benefits in Japan for the elderly in 2 lightest eligibility levels, which aim to improve and maintain their skills of independent living [34]. Meanwhile, given the importance of informal carers help and their views, more assistance targeted to informal caregivers, such as training to enhance their skills and knowledge of taking care of the elderly and/or cash subsidies for caregivers with lower income, should be considered in the home and community-based service provision. This will help to alleviate the burden and increase the self-efficacy of caregivers [35] [36].

In addition, it was also found that cognitive impairment had correlation in opposite directions to the views of the elderly and caregivers. This result was similar to that of a study showing that divergence of preference for institutionalization was larger between elderly with cognitive impairment and their caregivers than cognitive intact ones [17]. Elders with cognitive impairment might be unaware of or deny their functional impairment, and more likely to lack insight 
of caregiver's stress [37]; also they prefer staying in a familiar environment. Thus, caregivers serving community-dwelling care recipient with cognitively impairment required additional attentions in the support.

The trend of views over time also caught attentions was that the elderly and caregivers were more likely to support the idea of the elderly living at home, reflecting the increasing popularity of ageing in place. This might be due to increasing community resources for the elderly care and government's advocacy on ageing in place in the past decades [38]. On the other hand, some elderly people tended to live at home even when their health deteriorates due to the relatively poor environment of residential care homes [39].

Several limitations of this study should be noted. Firstly, causal relationship was not identified in this study due to the cross-sectional design and the insufficient evidence of temporal relationship between opinions and above-mentioned factors. Secondly, information on the financial conditions of elderly applicants and their household was not available in the data source in consideration of confidentiality; hence only whether to make any trade-offs between daily life expenses and care services was used there as a proxy of their financial conditions. There are also other factors related to the characteristics of the previous service utilization, such as type, quantity and quality of such services; but this study mainly focused on the choice of relevant service. Thirdly, views on living arrangement were used to represent the decisions on the use of residential care services, but there still was a risk of inconsistency between opinions and behaviors $[40]$.

\section{Conclusion}

The view of living away from home could be weakened by informal caregivers' support and previous use of formal home and community-based services. To promote the concept of ageing in place in Hong Kong, more community-based LTC services should be provided to the elderly at early stage of their frailty to help them get familiar with the services and creating connections with the community care centers. Home and community-based services with subsidies from government and elder-care training targeting informal caregivers should also be taken into account, so as to empower them and reduce their care burden, especially for those serving elderly with cognitive impairment.

\section{Acknowledgements}

This research project (Project Number: 2017.A4.039.17C) is funded by the Public Policy Research Funding Scheme from Policy Innovation and Co-ordination Office of the Hong Kong Special Administrative Region Government. The authors would also like to thank Mr. Sebastian Shu-To Tse and Mr. Pik-Ming Pang, Social Welfare Department, Hong Kong Special Administrative Region government, for providing the anonymous MDS-HC assessment data records of older applicants of subsidized LTC services. 


\section{Conflicts of Interest}

The authors declare no conflicts of interest regarding the publication of this paper.

\section{References}

[1] Census \& Statistical Department (2017) Population Estimate: Vital Events. https://www.censtatd.gov.hk/hkstat/sub/sp150.jsp? subjectID=150\&tableID=004\&ID $=0 \&$ productType $=8$

[2] Census \& Statistical Department (2017) Hong Kong Population Projections 2017-2066. Hong Kong. https://www.censtatd.gov.hk/FileManager/EN/Content 1170/pop_proj 16based sli de.pdf

[3] Social Welfare Department (2017) District Elderly Community Centre Community Care and Support Services for the Elderly.

http://www.swd.gov.hk/en/index/site pubsvc/page elderly/sub csselderly/id distri ctel

[4] Wiles, J.L., Leibing, A., Guberman, N., et al. (2012) The Meaning of "Aging in Place" to Older People. The Gerontologist, 52, 357-366. https://doi.org/10.1093/geront/gnr098

[5] Huber, M. and Hennessy, P. (2005) Long-Term Care for Older People. OECD Publishing, Paris.

[6] Chui, E. (2009) Elderly Commission's Study on Residential Care Services for the Elderly. Elderly Commission, Boston.

https://www.elderlycommission.gov.hk/en/download/library/Residential\%20Care\% 20Services\%20-\%20Final\%20Report(eng).pdf

[7] Legislative Council (2015) Challenges of Population Ageing, in Research Brief. Legislative Council, Hong Kong.

https://www.legco.gov.hk/research-publications/english/1516rb01-challenges-of-po pulation-ageing-20151215-e.pdf

[8] Liu, T., Hao, X. and Zhang, Z. (2016) Identifying Community Healthcare Supports for the Elderly and the Factors Affecting Their Aging Care Model Preference: Evidence from Three Districts of Beijing. BMC Health Services Research, 16, 626. https://doi.org/10.1186/s12913-016-1863-y

[9] Lou, V., Chui, E., Leung, A., et al. (2011) Factors Affecting Long-Term Care Use in Hong Kong. Hong Kong Medical Journal, 17, 8-12.

[10] Cepoiu-Martin, M., Tam-Tham, H., Patten, S., et al. (2016) Predictors of Long-Term Care Placement in Persons with Dementia: A Systematic Review and Meta-Analysis. International Journal of Geriatric Psychiatry, 31, 1151-1171. https://doi.org/10.1002/gps.4449

[11] McCaffrey, N., Gill, L., Kaambwa, B., et al. (2015) Important Features of Home-Based Support Services for Older Australians and Their Informal Carers. Health \& Social Care in the Community, 23, 654-664. https://doi.org/10.1111/hsc.12185

[12] Kaambwa, B., Lancsar, E., McCaffrey, N., et al. (2015) Investigating Consumers' and Informal Carers' Views and Preferences for Consumer Directed Care: A Discrete Choice Experiment. Social Science \& Medicine, 140, 81-94.

https://doi.org/10.1016/j.socscimed.2015.06.034

[13] Gaugler, J.E., Kane, R.L., Kane, R.A., et al. (2003) Caregiving and Institutionalization of Cognitively Impaired Older People: Utilizing Dynamic Predictors of Change. The Gerontologist, 43, 219-229. https://doi.org/10.1093/geront/43.2.219 
[14] Kaye, H.S. and Williamson, J. (2014) Toward a Model Long-Term Services and Supports System: State Policy Elements. The Gerontologist, 54, 754-761. https://doi.org/10.1093/geront/gnu013

[15] Cohen-Mansfield, J. and Wirtz, P.W. (2007) Characteristics of Adult Day Care Participants Who Enter a Nursing Home. Psychology and Aging, 22, 354. https://doi.org/10.1037/0882-7974.22.2.354

[16] Woo, J., Ho, S.C., Yu, A., et al. (2000) An Estimate of Long-Term Care Needs and Identification of Risk Factors for Institutionalization among Hong Kong Chinese Aged 70 Years and over. Journals of Gerontology Series A: Biological and Medical Sciences, 55, 64. https://doi.org/10.1093/gerona/55.2.M64

[17] Chau, P.H., Kwok, T., Woo, J., et al. (2010) Disagreement in Preference for Residential Care between Family Caregivers and Elders Is Greater among Cognitively Impaired Elders Group than Cognitively Intact Elders Group. International Journal of Geriatric Psychiatry, 25, 46-54. https://doi.org/10.1002/gps.2296

[18] Andrew, T., Moriarty, J., Levin, E., et al. (2000) Outcome of Referral to Social Services Departments for People with Cognitive Impairment. International Journal of Geriatric Psychiatry, 15, 406-414.

https://doi.org/10.1002/(SICI)1099-1166(200005)15:5<406::AID-GPS122>3.0.CO;2$\underline{\mathrm{F}}$

[19] Gaugler, J.E., Kane, R.L., Kane, R.A., et al. (2005) Early Community-Based Service Utilization and Its Effects on Institutionalization in Dementia Caregiving. The Gerontologist, 45, 177-185. https://doi.org/10.1093/geront/45.2.177

[20] Eska, K., Graessel, E., Donath, C., et al. (2013) Predictors of Institutionalization of Dementia Patients in Mild and Moderate Stages: A 4-Year Prospective Analysis. Dementia and Geriatric Cognitive Disorders Extra, 3, 426-445. https://doi.org/10.1159/000355079

[21] Wattmo, C., Wallin, Å.K., Londos, E., et al. (2010) Risk Factors for Nursing Home Placement in Alzheimer's Disease: A Longitudinal Study of Cognition, ADL, Service Utilization, and Cholinesterase Inhibitor Treatment. The Gerontologist, 51, 17-27. https://doi.org/10.1093/geront/gnq050

[22] Whitlatch, C.J., Feinberg, L.F. and Stevens, E.J. (1999) Predictors of Institutionalization for Persons with Alzheimer's Disease and the Impact on Family Caregivers. Journal of Mental Health and Aging, 5, 275-288.

[23] Greene, V.L., Lovely, M.E. and Ondrich, J.I. (1993) Do Community-Based, Long-Term-Care Services Reduce Nursing Home Use? A Transition Probability Analysis. Journal of Human Resources, 28, 297-317. https://doi.org/10.2307/146205

[24] vanBilsen, P., Hamers, J., Groot, W., et al. (2008) The Use of Community-Based Social Services by Elderly People at Risk of Institutionalization: An Evaluation. Health Policy, 87, 285-295. https://doi.org/10.1016/j.healthpol.2007.12.015

[25] Gaugler, J.E. and Zarit, S.H. (2001) The Effectiveness of Adult Day Services for Disabled Older People. Journal of Aging and Social Policy, 12, 23-47. https://doi.org/10.1300/J031v12n02 03

[26] Sugimoto, K., Kashiwagi, M. and Tamiya, N. (2017) Predictors of Preferred Location of Care in Middle-Aged Individuals of a Municipality in Japan: A Cross-Sectional Survey. BMC Health Services Research, 17, 352. https://doi.org/10.1186/s12913-017-2293-1

[27] Axtell-Thompson, L.M. (2005) Consumer Directed Health Care: Ethical Limits to Choice and Responsibility. Journal of Medicine and Philosophy, 30, 207-226. https://doi.org/10.1080/03605310590926867 
[28] Ruggiano, N. (2012) Consumer Direction in Long-Term Care Policy: Overcoming Barriers to Promoting Older Adults' Opportunity for Self-Direction. Journal of Gerontological Social Work, 55, 146-159. https://doi.org/10.1080/01634372.2011.638701

[29] Nelson, P. (1970) Information and Consumer Behavior. Journal of Political Economy, 78, 311-329. https://doi.org/10.1086/259630

[30] Banaszak-Holl, J., Fendrick, A.M., Foster, N.L., et al. (2004) Predicting Nursing Home Admission: Estimates from a 7-Year Follow-Up of a Nationally Representative Sample of Older Americans. Alzheimer Disease \& Associated Disorders, 18, 83-89. https://doi.org/10.1097/01.wad.0000126619.80941.91

[31] Agüero-Torres, H., von Strauss, E., Viitanen, M., et al. (2001) Institutionalization in the Elderly: The Role of Chronic Diseases and Dementia. Cross-Sectional and Longitudinal Data from a Population-Based Study. Journal of Clinical Epidemiology, 54, 795-801. https://doi.org/10.1016/S0895-4356(00)00371-1

[32] InterRAI. Home Care (HC). Instruments. http://www.interrai.org/home-care.html

[33] Meng, D., Xu, G., He, L., et al. (2017) What Determines the Preference for Future Living Arrangements of Middle-Aged and Older People in Urban China? PLoS ONE, 12, e0180764. https://doi.org/10.1371/journal.pone.0180764

[34] Olivares-Tirado, P. and Tamiya, N. (2013) Trends and Factors in Japan's Long-Term Care Insurance System: Japan’s 10-Year Experience. Springer Science \& Business Media, Berlin. https://doi.org/10.1007/978-94-007-7875-7

[35] Graff, M.J., Vernooij-Dassen, M.J., Thijssen, M., et al. (2006) Community Based Occupational Therapy for Patients with Dementia and Their Care Givers: Randomised Controlled Trial. BMJ, 333, 1196. https://doi.org/10.1136/bmj.39001.688843.BE

[36] Mossello, E., Caleri, V., Razzi, E., et al. (2008) Day Care for Older Dementia Patients: Favorable Effects on Behavioral and Psychological Symptoms and Caregiver Stress. International Journal of Geriatric Psychiatry, 23, 1066-1072. https://doi.org/10.1002/gps.2034

[37] Logsdon, R.G., Gibbons, L.E., McCurry, S.M., et al. (2002) Assessing Quality of Life in Older Adults with Cognitive Impairment. Psychosomatic Medicine, 64, 510-519. https://doi.org/10.1097/00006842-200205000-00016

[38] Chui, E. (2008) Ageing in Place in Hong Kong-Challenges and Opportunities in a Capitalist Chinese City. Ageing International, 32, 167-182. https://doi.org/10.1007/s12126-008-9015-2

[39] Audit Commission (2014) Provision of Long-Term Care Services for the Elderly. https://www.aud.gov.hk/pdf e/e63ch01sum.pdf

[40] Chiu, L., Tang, K.Y., Liu, Y.H., et al. (1998) Consistency between Preference and Use of Long-Term Care among Caregivers of Stroke Survivors. Public Health Nursing, 15, 379-386. https://doi.org/10.1111/j.1525-1446.1998.tb00363.x 